\title{
Simulation-Based Medical Emergencies Education for Dental Students: A Three-Year Evaluation
}

\author{
Kyriaki Marti, Gurjit Sandhu, Lior Aljadeff, Rachel Greene, Amy B. Lesch, John M. Le, \\ Harold M. Pinsky, Deborah M. Rooney
}

\begin{abstract}
This aim of this study was to develop and evaluate a simulation program for dental students to supplement a lecturebased medical emergencies course. Students' self-reported knowledge, experience, confidence, and ability regarding medical emergencies were assessed as program outcomes. For three years (in 2014, 2015, and 2016), all second-year students (N=333) at one U.S. dental school were randomly assigned to groups of 15 and participated in 15 simulated clinical scenarios. All students completed a 21-item pre-post survey and rated their knowledge, experience, and confidence using simulated emergencies. Following the intervention, students' ability to complete critical actions was also peer-assessed using a ten-item checklist. Four open-ended questions were included on the post-intervention survey for acquisition of additional data. For all years, students' self-reported measurements significantly improved with high practical impact $(\mathrm{p} \leq 0.001, \mathrm{~g}=|0.62,3.93|)$, with the exception of calling 911 (knowledge). Peer-rated performance indicated the students were deficient ( $<75 \%$ success) in the following: inhaler use, dose of local anesthetic, dose of epinephrine, and EpiPen use. Content analysis of students' comments pointed to areas that need improvement but found high satisfaction with the program. These findings indicate that this program improved students' knowledge, experience, and confidence using simulated medical emergencies.
\end{abstract}

Kyriaki Marti, DMD, MD, MHPE, PhD, CHSE, FEBOMFS, is Clinical Assistant Professor, Department of Oral and Maxillofacial Surgery, Department of Periodontics and Oral Medicine, and Department of Cariology, Restorative Sciences, and Endodontics, University of Michigan School of Dentistry; Gurjit Sandhu, PhD, is Assistant Professor, Department of Surgery and Department of Learning Health Sciences, University of Michigan Medical School; Lior Aljadeff, DDS, MD, is Oral and Maxillofacial Surgery Resident, Division of Oral and Maxillofacial Surgery, University of Texas Southwestern Medical Center/Parkland Memorial Hospital; Rachel Greene, DDS, is Clinical Instructor, Department of Restorative Dentistry, University of Washington School of Dentistry; Amy B. Lesch, DDS, is Resident, Pediatric Dentistry and Dental Public Health Residency Program, Department of Pediatric Dentistry, University of Iowa College of Dentistry \& Dental Clinics; John M. Le, DDS, is Oral and Maxillofacial Surgery Resident, University of Alabama at Birmingham; Harold M. Pinsky, DDS, is Adjunct Clinical Lecturer, Department of Periodontics and Oral Medicine, University of Michigan School of Dentistry; and Deborah M. Rooney, PhD, is Assistant Professor, Department of Learning Health Sciences, University of Michigan Medical School. Direct correspondence to Dr. Kyriaki Marti, University of Michigan School of Dentistry, 1011 N. University Ave., Ann Arbor, MI 48109-1078; 734-647-7852; kyriaki@med.umich.edu.

Keywords: dental education, medical emergencies, simulation, role-playing, interdisciplinary education

Submitted for publication 7/10/18; accepted 12/20/18; first published online 4/8/19

doi: 10.21815/JDE.019.084

A s health professionals, dentists should be prepared to recognize and manage common medical emergencies that may arise in the dental office or dental school clinic. ${ }^{1}$ Historically, predoctoral training for in-office medical emergencies at the University of Michigan School of Dentistry (UMSoD) has consisted of a lecturebased course. ${ }^{2,3}$ While the Commission on Dental Accreditation (CODA) standards require that dental graduates, faculty, and staff involved with direct patient care be competent in managing common medical emergencies in the dental clinic, ${ }^{4}$ our students have continued to reveal skill deficiencies following preclinical training, such as locating and administering medical equipment. ${ }^{5,6}$ Le et al. found that only $50 \%$ of third- and fourth-year dental students could administer oxygen properly during simulation. ${ }^{5} \mathrm{Ad}$ ditionally, Pinsky et al. found that dental students had limited knowledge of where basic medical equipment was located in the dental school clinics. ${ }^{6}$ Furthermore, a survey by Albelaihi et al. reported that only $37 \%$ of dental students and interns were confident in the management of a medical emergency in the dental office. ${ }^{7}$

Alkhater and Al-Harthy reported the need to integrate a course about medical emergencies 
management at dental clinics and added a simulated medical emergency response experience for dental students. ${ }^{8}$ While few studies have evaluated a simulation component in medical emergencies training for predoctoral dental students, simulation-based training programs have been developed and demonstrated value in dental curricula., ${ }^{2,-12}$ In addition, researchers have applied lessons learned from aviation's simulated crew resource management training with a shared mental model to improve clinical care. ${ }^{6}$ Similarly, medical educators have demonstrated a direct relationship and transfer of knowledge between simulation and patient care. ${ }^{13-16}$

We incorporated a hybrid simulation-based training model into the existing dental curriculum. This training was an interdepartmental collaborative effort among the Department of Cariology, Restorative Sciences, and Endodontics, Department of Periodontics and Oral Medicine, Department of Oral and Maxillofacial Surgery, and the Leadership Pathway program. This training model was designed to prepare second-year dental students to manage common in-office medical emergencies prior to the start of their clinical experience in the patient clinics. Role-playing as an educational method has been found to be an effective method for learner acquisition of knowledge, attitudes and communication skills. ${ }^{17}$ It draws on Kolb's experiential learning theory ${ }^{18}$ and Kneebone's theory-based approach to learning clinical skills in simulation, which focuses on supporting learners with expert tutoring in an authentic professional context while considering the emotional elements of learning. ${ }^{19}$

Based on our review of the literature, we were unable to find any reported peer assessment tools used in dental education for evaluation of skills during simulation-based medical emergencies training to aid in the transition from lectures to clinical handson skills. The medical topic categories included in our training model, described as subcategories by Malamed, were unconsciousness, respiratory distress, altered consciousness, seizures, drug-related emergencies, chest pain. and cardiac arrest. ${ }^{20}$

This aim of our study was to develop and evaluate a simulation program for dental students to supplement a lecture-based medical emergencies course. We assessed the program's impact on our students' knowledge, skills, and attitudes in recognizing and managing common in-office medical emergencies and used the findings to identify learning gaps through the use of peer assessment.

\section{Methods}

The Health and Behavioral Sciences Institutional Review Board of the University of Michigan determined this study was exempt from oversight. The new curriculum component was initiated by the teaching faculty of UMSoD.

During the winter semester of 2014, 2015, and 2016, all second-year students $(\mathrm{N}=333)$ participated in the novel simulation-based medical emergencies program. Prior to the intervention, all students had completed basic life support (BLS) training within the previous 18 months and attended the lecturebased medical emergencies course (Dent 607) in preparation for the simulation-based session. Program evaluation was based on the context, input, process, and product (CIPP) evaluation model, which offers a comprehensive evaluation approach focusing on program improvement and discussing outcomes and uses both formative and summative information and presents them to the stakeholders. Stufflebeam and Shinkfield stated that proactive application of the model can facilitate decision making and quality assurance, and faculty can retrospectively use it to continually reframe and summarize a project's value and significance. ${ }^{21}$

\section{Intervention}

All the students in the study were randomly assigned a date for their simulation session. Previous practical training of students consisted of cardiopulmonary resuscitation (CPR) in a non-dental environment. Fifteen students participated in each simulation session held in the preclinical setting and were randomly divided into five groups. In a three-hour period, the students rotated through five stations centered on the following themes: altered consciousness, chest pain, drug-related emergencies, unconsciousness, and respiratory distress. Each station lasted approximately 30 minutes. At each station, students engaged in three scenarios and performed three roles (team leader, team member, and patient) following a written script. A group of faculty members and postgraduate residents from the UMSoD and the University of Michigan Emergency Medicine Department facilitated the sessions by supervising the students at each station and providing debriefs.

One of the scenarios covered airway management and required the use of CPR on a mannequin. Before completion of all the scenarios, the students were assessed individually by a single select peer 
during one of two standardized "megacode" scenarios (comprehensive medical emergency scenarios). The simulation session concluded with a focus group in which facilitators and students discussed learning gaps and potential improvements to the program.

\section{Assessment and Evaluation}

We used two assessment tools in this study to evaluate the benefit of the training experience on students' perceptions and learning outcomes and their ability to manage medical emergencies. First, a two-part, 25-item student questionnaire measured students' self-reported knowledge, experience, and confidence in simulated medical emergencies as adapted from the participant perception indicator (PPI) in the Merlot system at the University of Michigan. ${ }^{22}$ Part one of the questionnaire consisted of four demographic questions. Part two consisted of 21 items, in which students were asked to rate their knowledge, experience, and confidence in seven domains associated with medical emergencies. Part two items were scored using five-point rating scales that ranged from 1 (less) to 5 (more). The postintervention assessment tool consisted of the same 25 items and four additional items. These were: 1) How comfortable were you during the actual simulation session? 2) What specific advice would you give to help your instructor improve your learning in this simulation session? 3) What other ideas would you suggest to improve this course? 4) Do you feel that you need to have more simulation sessions in the future? All 29 items informed the program evaluation.

The second tool (for peer performance assessment) was used to evaluate learning outcomes and to identify specific learning gaps. Because our literature review found no existing checklists relevant to the assessment of dental students' ability to manage medical emergencies, we adapted a dental checklist described by Pinsky et al. that applied best practices used in airline crew resource management (CRM) to dentistry. ${ }^{6}$ There is significant value in borrowing CRM concepts from the airline industry, as it has been incorporated by the medical profession and health systems, as well as in the dental practice. Two of the authors (HMP and KM) adapted Pinsky's checklist for relevance, which resulted in a dichotomously scored (yes $=1$, no $=0$ ), ten-item peer performance checklist that targeted the intended construct: ability to manage medical emergencies. Using the checklist, students were paired into teams of two, in which each student assessed his or her teammate's ability to complete the ten skills required during one of two megacodes.

\section{Statistical Analyses}

We used several methods to gain as much information as possible about learning outcomes and students' perceptions of the program. First, to evaluate the simulation-based program's impact on students' perceived knowledge, experience, and confidence in simulated medical emergencies, we compared students' pre- and post-intervention student questionnaire ratings using a paired Student t-test following confirmation of normal distribution of data. Mean differences and p-values were reported along with effect sizes. Statistical significance was set at $\mathrm{p} \leq 0.05$. Effect size was estimated using Hedge's g, similar to Cohen's d, but with mathematical correction for bias. ${ }^{23}$ For our results, a g-value of 0.5 was considered to have moderate practical effect and indicated the difference between the two groups was 0.5 standard deviation apart. Values over 0.8 were considered large.

Following training, we tracked outstanding learning gaps by calculating completion rates of the ten items (tasks) on the peer performance assessment checklist, which was used to measure students' post-intervention ability to manage medical emergencies. We used a 75\% "pass" criterion for successful checklist completion based on simulation curriculum assessment previously reported (objective structured assessment of technical skills). ${ }^{24}$

\section{Results}

All 333 students in the three years $(2014 \mathrm{n}=113$, $2015 n=113,2016 n=107$ ) participated in the program and the assessments. For all three training years, the students' self-reported knowledge was significantly higher following the training experience for six of the seven items with high practical impact, $p \leq 0.001$, $\mathrm{g}=|0.62,1.99|$ (Table 1). For one item (calling 911), students' scores improved following training for each of the three years, but the differences were not statistically significant. For all three years, the students' self-reported experience and confidence ratings were also significantly higher following training, with high practical impact, $\mathrm{p}=0.001, \mathrm{~g}=|0.74,3.93|$.

For the descriptive part of our study, we conducted a content analysis of the students' responses on the four open-ended questions using the NVivo qualitative data analysis Software v. 10 (QSR International Pty. Ltd., Melbourne, Australia). ${ }^{25}$ Our approach was based on an inductive process that moves from the specific to the general, so that responses to four 
Table 1. Pre-post intervention differences $(\Delta)$ in self-report mean ratings across knowledge, experience, and confidence domains for three academic years: YR1 ( $=113)$, YR2 $(n=113)$, YR3 $(n=107)$

\begin{tabular}{|c|c|c|c|c|c|c|c|c|c|}
\hline \multirow[b]{2}{*}{ Item } & \multicolumn{3}{|c|}{ Knowledge } & \multicolumn{3}{|c|}{ Experience } & \multicolumn{3}{|c|}{ Confidence } \\
\hline & $\begin{array}{l}\text { YR1 } \Delta \\
\text { (g) }\end{array}$ & $\begin{array}{c}\text { YR2 } \Delta \\
\text { (g) }\end{array}$ & $\begin{array}{c}\text { YR3 } \Delta \\
\text { (g) }\end{array}$ & $\begin{array}{l}\text { YR1 } \Delta \\
\text { (g) }\end{array}$ & $\begin{array}{l}\text { YR2 } \Delta \\
\text { (g) }\end{array}$ & $\begin{array}{l}\text { YR3 } \Delta \\
\text { (g) }\end{array}$ & $\begin{array}{l}\text { YR1 } 1 \Delta \\
\text { (g) }\end{array}$ & $\begin{array}{c}\text { YR2 } \Delta \\
\text { (g) }\end{array}$ & $\begin{array}{c}\text { YR3 } \Delta \\
\text { (g) }\end{array}$ \\
\hline 1. Find emergency kit & $\begin{array}{c}2.19 \\
(1.99)\end{array}$ & $\begin{array}{c}1.75 \\
(1.64)\end{array}$ & $\begin{array}{c}1.79 \\
(1.77)\end{array}$ & $\begin{array}{c}2.39 \\
(2.29)\end{array}$ & $\begin{array}{c}1.69 \\
(1.95)\end{array}$ & $\begin{array}{c}2.01 \\
(1.98)\end{array}$ & $\begin{array}{l}2.22 \\
(2.01)\end{array}$ & $\begin{array}{c}1.96 \\
(1.50)\end{array}$ & $\begin{array}{c}1.81 \\
(1.88)\end{array}$ \\
\hline 2. Call 911 & $\begin{array}{c}0.25^{*} \\
(\mathrm{~ns})\end{array}$ & $\begin{array}{c}0.17^{*} \\
(\mathrm{~ns})\end{array}$ & $\begin{array}{c}0.30^{*} \\
(\mathrm{~ns})\end{array}$ & $\begin{array}{c}1.53 \\
(1.08)\end{array}$ & $\begin{array}{c}0.65 \\
(1.11)\end{array}$ & $\begin{array}{c}1.38 \\
(1.04)\end{array}$ & $\begin{array}{c}0.59 \\
(0.51)\end{array}$ & $\begin{array}{c}1.54 \\
(0.58)\end{array}$ & $\begin{array}{c}0.70 \\
(0.64)\end{array}$ \\
\hline 3. Assemble OET (emergency team) & $\begin{array}{c}1.82 \\
(1.61)\end{array}$ & $\begin{array}{c}1.97 \\
(1.98)\end{array}$ & $\begin{array}{c}1.70 \\
(1.69)\end{array}$ & $\begin{array}{c}2.06 \\
(1.87)\end{array}$ & $\begin{array}{c}1.97 \\
(2.15)\end{array}$ & $\begin{array}{l}2.10 \\
(2.11)\end{array}$ & $\begin{array}{c}1.94 \\
(1.66)\end{array}$ & $\begin{array}{c}2.18 \\
(1.84)\end{array}$ & $\begin{array}{c}1.66 \\
(1.54)\end{array}$ \\
\hline 4. Maintain airway & $\begin{array}{c}1.14 \\
(0.99)\end{array}$ & $\begin{array}{c}1.02 \\
(1.04)\end{array}$ & $\begin{array}{c}1.31 \\
(1.31)\end{array}$ & $\begin{array}{c}1.67 \\
(1.42)\end{array}$ & $\begin{array}{c}1.19 \\
(1.64)\end{array}$ & $\begin{array}{c}1.78 \\
(1.54)\end{array}$ & $\begin{array}{c}1.57 \\
(1.31)\end{array}$ & $\begin{array}{c}1.82 \\
(0.41)\end{array}$ & $\begin{array}{c}1.51 \\
(1.38)\end{array}$ \\
\hline 5. Find and use $\mathrm{O}_{2}$ (dose) & $\begin{array}{c}1.86 \\
(1.68)\end{array}$ & $\begin{array}{c}1.64 \\
(1.63)\end{array}$ & $\begin{array}{c}1.49 \\
(1.43)\end{array}$ & $\begin{array}{c}2.11 \\
(1.79)\end{array}$ & $\begin{array}{c}2.00 \\
(1.86)\end{array}$ & $\begin{array}{c}1.99 \\
(1.76)\end{array}$ & $\begin{array}{c}2.03 \\
(1.79)\end{array}$ & $\begin{array}{c}2.14 \\
(1.85)\end{array}$ & $\begin{array}{c}1.90 \\
(1.81)\end{array}$ \\
\hline 6. Choose appropriate medication & $\begin{array}{c}1.35 \\
(1.27)\end{array}$ & $\begin{array}{c}1.17 \\
(1.23)\end{array}$ & $\begin{array}{c}1.06 \\
(1.02)\end{array}$ & $\begin{array}{c}1.58 \\
(1.53)\end{array}$ & $\begin{array}{c}1.25 \\
(1.58)\end{array}$ & $\begin{array}{c}1.37 \\
(1.32)\end{array}$ & $\begin{array}{c}1.38 \\
(1.29)\end{array}$ & $\begin{array}{c}1.48 \\
(1.18)\end{array}$ & $\begin{array}{c}1.25 \\
(1.15)\end{array}$ \\
\hline 7. Measure vital signs & $\begin{array}{c}0.81 \\
(0.77)\end{array}$ & $\begin{array}{c}0.65 \\
(0.68)\end{array}$ & $\begin{array}{c}0.49 \\
(0.62)\end{array}$ & $\begin{array}{c}1.19 \\
(1.01)\end{array}$ & $\begin{array}{c}0.98 \\
(0.80)\end{array}$ & $\begin{array}{c}0.91 \\
(0.88)\end{array}$ & $\begin{array}{c}1.16 \\
(0.98)\end{array}$ & $\begin{array}{c}0.92 \\
(0.93)\end{array}$ & $\begin{array}{c}0.71 \\
(0.73)\end{array}$ \\
\hline
\end{tabular}

ns=non-significant mean differences so $g$ not calculated

*Statistical differences for all items $p \leq 0.001$, except Call 911 for Knowledge $(p>0.05)$

open-ended questions were coded and categorized under higher order headings. From the resulting categories, we inductively abstracted a general description informed by learning gaps or areas of interest. ${ }^{26}$

We identified four broad categories of students' comments (Table 2): learner comfort level, curriculum structure, facilitation, and pedagogy. There was also a separate category (other) focused on the use of simulated patients and further simulation-based training to improve students' ability to communicate with first responders (calling 911). ${ }^{27}$ Content analysis showed that 213 students reported various levels of comfort during simulation. The students also discussed their perceptions about potential use of simulated patients and suggested further training in calling 911 . They commented on faculty participation and proposed repetition of the course at a different time in the curriculum, as well as noting the perceived value of this course.

Examination of post-intervention peer-rated performance showed that some students continued to have difficulty with five skills (Table 3 ). With success rates of $65 \%$ or less, those skills were inhaler use (63.1\% success rate), dose of local anesthetic $(65.0 \%)$, dose of epinephrine $(60.0 \%)$ EpiPen use (63.2\%), and finding $\mathrm{O}_{2}$ and using mask (45.6\%). The remaining six skills were performed adequately ( $77.3 \%$ to $98.8 \%$ success rates). Students evaluated each other with the checklist on successfully completing or not completing ten skills. In the lower percentage areas, students perceived their peers needed improvement in those skills.

\section{Discussion}

Using lessons learned from other clinical disciplines and aviation, ${ }^{6,13,27}$ we developed and evaluated a novel simulation-based program for the predoctoral dental curriculum to prepare second-year dental students for the management of in-office medical emergencies. Results from this study demonstrated a statistically significant and positive effect of the program on the students' self-reported knowledge, experience, and confidence for most skills. Across the three years, we found discrepancies on items such as calling 911 . Due to the complexity of the course, in the areas of staffing, timing in the curriculum, or potentially subtle variation in instructions, we find the interpretation of these findings to be challenging. Although there were some areas that required more focused training in the future, our findings were consistent with the study by Wald et al., which identified significant improvement in dental students' self-reported comfort in managing three clinical scenarios following simulation training. ${ }^{9}$

Newby et al. found that the use of simulation improved health care education and patient safety. ${ }^{28}$ 
Table 2. Examples of students' comments after simulation experience, with number of comments by category and code

Category Code Numbles

Curriculum Well organized, Sufficient structure training

Equipment and materials, Case clarity, Improve briefing and instructions, Improve logistics, Improve scenario, More time, More training, Repeat in semester or annually, Start in year one

Learner Comfortable, Very comfortable, comfort Mostly/somewhat comfortable

level

Confidence

Uncomfortable, Somewhat uncomfortable

Awkward, Nervous, Unprepared, Worried, Stressful

Pedagogy Optimal learning, Supportive learning, Environment, Experiential learning, Building on previous experience

Assessment

Facilitation Faculty, Instructors, Staff

Other Call 911/simulated patients
"The background info we received and experiences helped prepare us."

"The material provided by faculty was well described. The faculty member explained well all the scenarios."

"I think having the D4 mentors was an excellent resource. I also think that having a quick briefing with the patient before each scenario might be helpful."

"Have more than one session and have this throughout dental school year, beginning in the first year. Have more scenarios and even a more exact protocol type like procedures for each. I feel as though these need to be ingrained."

"The experience was very comfortable as we were able to work with our classmates and rotate through the scenarios. The upper classmen were also very helpful in answering questions."

"Very comfortable, good learning environment."

"I was very confident; indeed [it was] very helpful to prepare for future medical emergencies."

"I was nervous during the simulation experiences at the beginning but became much more confident as the scenarios progressed."

"It was a little awkward running through each scenario without prior briefing on the situation."

"During the simulation experience I liked the critical critique and what we needed to do and what we could do better."

"These types of sessions are very helpful. It is good to act them out and review the things learned in class in practice."

"Would love more assessments/testing scenarios."

"Great way to learn and realize what we do not know. It is hard to ask questions in class when you don't know what you don't know."

"Our station with a resident facilitating felt like one of the most worthwhile because we left feeling like we did not miss/overlook anything."

"For some reason I get very nervous when calling 911. I have no problem talking with the patient, but I feel nervous when calling!"

"I would like to see a simulated patient experience in which it was a lifelike scenario after this course, so we could apply our knowledge."

Table 3. Peer-rated student completion rates for skills performed in post-intervention simulated setting, years 1-3

\begin{tabular}{lccc} 
Action Completed & $\begin{array}{c}\text { Year 1 } \\
\% \text { Complete }\end{array}$ & $\begin{array}{c}\text { Year 2 } \\
\% \text { Complete }\end{array}$ & $\begin{array}{c}\text { Year 3 } \\
\% \text { Complete }\end{array}$ \\
\hline Find $\mathrm{O}_{2}$ and use mask & $93.9 \%$ & $45.6 \%$ & $98.8 \%$ \\
Airway management & $91.3 \%$ & $96.0 \%$ & $95.8 \%$ \\
Measurement of vital signs & $94.0 \%$ & $94.1 \%$ & $96.8 \%$ \\
Find emergency kit & $85.7 \%$ & $93.1 \%$ & $96.8 \%$ \\
Locate and use AED & $77.3 \%$ & $86.5 \%$ & $91.8 \%$ \\
Inhaler use & $63.1 \%$ & $69.9 \%$ & $75.0 \%$ \\
Dose of local anesthetic & $65.0 \%$ & $84.1 \%$ & $81.2 \%$ \\
Dose of epinephrine & $60.0 \%$ & $90.0 \%$ & $83.6 \%$ \\
EpiPen use & $63.2 \%$ & $90.0 \%$ & $83.1 \%$ \\
Team assembling & $95.7 \%$ & $91.0 \%$ & $92.8 \%$
\end{tabular}


Similarly, we posited that these skills may be transferable into clinical practice, although further studies are needed as called for by Ruesseler et al. ${ }^{29}$ Students' perceptions in our study also supported our overall understanding of student satisfaction with implementation of the simulations, although they pointed out the need for more training and facilitation by more faculty members or residents. This finding was consistent with the previously reported satisfaction after simulation training by medical students. ${ }^{30}$ Our students noted in their comments the need for targeted "call 911" training and the potential use of simulated patients at some point in the medical emergencies program. These results were consistent with students' comments, which noted discrepancies in calling 911. Our students also clearly expressed the need for more simulation-based medical emergencies training in the predoctoral curriculum. There are two studies in which dental students also reported the need for more intensive education in medical emergencies. ${ }^{31,32}$

Most importantly, our program has a number of distinctive features that may be used to promote simulation-based education in dental education. Facilitated by faculty members from three UMSoD departments and initiated by Leadership Pathway dental students, the program was intended to reflect and promote intraprofessional teaching collaboration. ${ }^{33,34}$ Also, because the program consisted of free-standing, learner-directed sessions, it required minimal faculty facilitation and maximized faculty time. Finally, program evaluations included students' self-assessment and a final peer assessment of students' skills, which were found to reasonably correlate with other measures of ability in medical education. ${ }^{35}$ To date, there are no reported peer assessment tools used in dental education for the assessment of skills performed during simulation-based medical emergencies training. Our work also demonstrates the use, and potential value, of peer assessment in this setting. Program adjustments based mainly on students' comments on the self-assessment questionnaire were simulationbased training in contacting and communicating with Emergency Medical Service via phone and on-site training in locating medical emergency equipment in the clinical setting.

There are a number of limitations to consider in this program evaluation. Most notably, although it covered three years, our evaluation was limited to one specific location, limiting the generalizability of our findings. There were also challenges associated with implementation of the program that may have affected the outcomes. These challenges included limited interdepartmental faculty time availability, resulting in some sessions being understaffed; nonstandardized dental faculty training on medical emergencies facilitation, which may have introduced variability into teaching and debriefing methods; and difficulties in interdepartmental schedule coordination that resulted in having weekly staffing requirements determined shortly before the sessions. Fortunately, these issues were mitigated by having a core faculty group that facilitated the program, which included faculty members experienced in simulation teaching (with five to 20 years of expertise). Furthermore, the collaborative aspect of the course permitted the recruitment of additional dental faculty members with complimentary areas of expertise as well as postgraduate residents.

There were also limitations associated with the research methods. First, because the data were de-identified to ensure anonymity, deeper analysis at the learner level was prohibited. As a result, specific learning gaps at the individual learner level could be neither identified nor addressed. Second, our peer assessments were limited to one encounter per learner. Increasing the number of encounters observed may have improved the quality of ratings and allowed for estimation of peer assessment reliability as noted by Norcini. ${ }^{35}$

In this study, we identified learning gaps in the predoctoral dental medical emergencies training at our institution, which will be targeted in revised versions of this program. Future developments of this course will include refinement and standardization of the curriculum (such as maximizing briefing time, examining opportunities for repetition of training and/or in-situ training, and aiming for more facilitators in the course). In addition, resources based on experience gained during the program will be used to form a "train-the-trainer" faculty development course as described by Rogers et al. ${ }^{36}$ This course will train all the faculty in formative assessment techniques and improve debriefing and feedback practices.

The lessons learned through the program's development and implementation indicate it offers the opportunity to include learners from other health care fields (e.g., medicine, nursing, pharmacy) in the course. Doing so would also offer the opportunity to include faculty members from those health professions. Simulation-based learning can be especially beneficial in interprofessional education (IPE) activities because of its experiential nature, and previous 
studies have found that learners reported high overall satisfaction and strong positive attitudes about teamwork, collaboration, and patient-centeredness gained through participation in simulation-based IPE. ${ }^{33,34}$

We are planning to have regular emergency management refresher training in skills not routinely used. This step is the natural evolution of simulationbased medical emergency training. While this course, by design, is for initial introduction to medical emergency management, future targeted audiences include dental students and faculty. A recent study proposed incorporating periodic emergency drills in dental settings, along with continuing education courses, to help dentists manage medical emergencies. ${ }^{37}$ Therefore, we plan to disseminate the lessons learned in the program's development through continuing education courses for dentists in the community. Cheng et al. recently discussed a learner-centered balanced approach for a faculty development course, presenting how simulation instructors in health care can implement strategies to enhance learner-centeredness during debriefing. ${ }^{38}$ By encouraging the participation of dentists as learners in this training, lessons learned may also be transferred to current dental education.

\section{Conclusion}

The results of our study showed that this lowcost simulation-based program improved dental students' knowledge, experience, and confidence in simulated medical emergencies. Distinctive features of the program were intraprofessional faculty collaborations and the checklist used for peer evaluation. We anticipate further refinement of this scenariobased role-playing training program to better target the learning gaps identified in this program evaluation in order to improve our dental students' competence at managing medical emergencies.

\section{Acknowledgments}

The authors extend their sincere thanks to the course director, Dr. Mark Fitzgerald, Associate Dean for Outreach and Community Dentistry, and Dr. Steven Stefanac, Senior Associate Dean, for facilitating the conduct of this study. They also thank Dr. Laura Hopson, Residency Program Director, University of Michigan Emergency Medicine, and the residents for their valuable collaboration. They thank Dr. Russell Taichman, Associate Dean of Research, and Dr. Domenica Sweier, Associate Professor.

\section{Disclosure}

The authors reported no conflicts of interest.

\section{REFERENCES}

1. Anders PL, Comeau RL, Hatton M, Neiders ME. The nature and frequency of medical emergencies among patients in a dental school setting. J Dent Educ 2010;74(4):392-6.

2. Balmer MC. A dental undergraduate course for the management of medical emergencies in dental practice. Eur J Dent Educ 2008;12(4):239-46.

3. Clark MS, Wall BE, Tholström TC, et al. A twenty-year follow-up survey of medical emergency education in U.S. dental schools. J Dent Educ 2006;70(12):1316-9.

4. Commission on Dental Accreditation. Accreditation standards for dental education programs. Chicago: American Dental Association, 2018.

5. Le TT, Scheller EL, Pinsky HM, et al. Ability of dental students to deliver oxygen in a medical emergency. J Dent Educ 2009;73(4):499-508.

6. Pinsky HM, Le JM, Sweier DG, Marti K. Dental students' ability to locate emergency equipment: lessons learned from aviation. Eur J Dent Educ 2018;22(1):e19-25.

7. Albelaihi HF, Alweneen AI, Ettish A, Alshahrani FA. Knowledge, attitudes, and perceived confidence in the management of medical emergencies in the dental office: a survey among the dental students and interns. J Int Soc Prev Community Dent 2017;7(6):364-9.

8. Alkhater M,Al-Harthy M. The competence of dental staff and students to deal with medical emergencies at UQUDENT. Int J Sci Res 2017;6(2):1147-50.

9. Wald DA, Wang A, Carroll G, et al. An office-based emergencies course for third-year dental students. J Dent Educ 2013;77(8):1033-41.

10. Buchanan JA. Use of simulation technology in dental education. J Dent Educ 2001;65(11):1225-31.

11. Perry S, Bridges SM, Burrow MF. A review of the use of simulation in dental education. Simul Healthcare 2015;10(1):31-7.

12. Tanzawa T, Futaki K, Kurabayashi H, et al. Medical emergency education using a robot patient in a dental setting. Eur J Dent Educ 2013;17(1):e114-9.

13. McGaghie WC, Issenberg SB, Cohen ER, et al. Does simulation-based medical education with deliberate practice yield better results than traditional clinical education? A meta-analytic comparative review of the evidence. Acad Med 2011;86(6):706-11.

14. McGaghie WC, Issenberg SB, Petrusa ER, Scalese RJ. A critical review of simulation-based medical education research: 2003-09. Med Educ 2010;44(1):50-64.

15. Moazed F, Cohen ER, Furiasse N, et al. Retention of critical care skills after simulation-based mastery learning J Grad Med Educ 2013;5(3):458-63.

16. Motola I, Devine LA, Chung HS, et al. Simulation in health care education: a best evidence practical guide. AMEE guide no. 82. Med Teach 2013;35(10):e1511-30.

17. El Tantawi MM, Abdelaziz H, AbdelRaheem AS, Mahrous AA. Using peer-assisted learning and role-playing to teach generic skills to dental students: the health care simulation model. J Dent Educ 2014;78(1):85-97. 
18. Kolb DA. Experiential learning: experience as the source of learning and development. Englewood Cliffs, NJ: Prentice Hall, 1984.

19. Kneebone R. Evaluating clinical simulations for learning procedural skills: a theory-based approach. Acad Med 2005;80(6):549-53.

20. Malamed SF. Medical emergencies in the dental office. $7^{\text {th }}$ ed. St. Louis, MO: Elsevier, 2014.

21. Stufflebeam D, Shinkfield A. Evaluation theory, models, and applications. San Francisco: Jossey-Bass/John Wiley \& Sons, 2007.

22. Merlot System. At: www.merlot.org/merlot/viewMaterial. htm?id=80037. Accessed 2 March 2016.

23. Lakens D. Calculating and reporting effect sizes to facilitate cumulative science: a practical primer for t-tests and ANOVAs. Front Psychol 2013;4:863.

24. Chipman JG, Schmitz CC. Using objective structured assessment of technical skills to evaluate a basic skills simulation curriculum for first-year surgical residents. J Am Coll Surg 2009;209(3):364-70.

25. Pandey KM. Research methodology. In: Paradigms of knowledge management: studies in systems, decision, and control. Vol. 60. New Delhi: Springer, 2016.

26. Shaughness G, Georgoff PE, Sandhu G, et al. Assessment of clinical feedback given to medical students via an electronic feedback system. J Surg Res 2017;218:174-9.

27. Meischke H, Painter I, Turner AM, et al. Protocol: simulation training to improve 9-1-1 dispatcher identification of cardiac arrest. BMC Emerg Med 2016;16(1):9.

28. Newby JP, Keast J, Adam WR. Simulation of medical emergencies in dental practice: development and evaluation of an undergraduate training programme. Aust Dent J 2010;55(4):399-404.
29. Ruesseler M, Weinlich M, Müller MP, et al. Simulation training improves ability to manage medical emergencies. Emerg Med J 2010;27(10):734-8.

30. Ten Eyck RP, Tews M, Ballester JM. Improved medical student satisfaction and test performance with a simulation-based emergency medicine curriculum: a randomized controlled trial. Ann Emerg Med 2009;54(5):684-91.

31. Bell G, James H, Kreczak H, Greenwood M. Final-year dental students' opinions of their training in medical emergency management. Prim Dent J 2014;3(1):46-51.

32. Carvalho RM, Costa LR, Marcelo VC. Brazilian dental students' perceptions about medical emergencies: a qualitative exploratory study. J Dent Educ 2008;72(11):1343-9.

33. Paige JT, Garbee DD, Brown KM, Rojas JD. Using simulation in interprofessional education. Surg Clin North Am 2015;95(4):751-66.

34. Reeves S, Perrier L, Goldman J, et al. Interprofessional education: effects on professional practice and health care outcomes (update). Cochrane Database Syst Rev 2013;28(3):CD002213.

35. Norcini JJ. Workplace assessment. In: Swanwick T. Understanding medical education: evidence, theory, and practice. 2nd ed. New York: Wiley-Blackwell, 2014.

36. Rogers DA, Peterson DT, Ponce BA, et al. Simulation and faculty development. Surg Clin North Am 2015;95(4):729-37.

37. de Bedout T, Kramer K, Blanchard S, et al. Assessing the medical emergency preparedness of dental faculty, residents, and practicing periodontists: an exploratory study. J Dent Educ 2018;82(5):492-500.

38. Cheng A, Morse KJ, Rudolph J, et al. Learner-centered debriefing for health care simulation education: lessons for faculty development. Simul Healthcare 2016;11(1):32-40. 